\title{
Article
}

\section{Ion-Exchange Reaction of n-Pentylamine-Intercalated Layered Perovskite with Alkali and Alkaline Earth Metal Ions in Aqueous Solution}

\author{
Yoshiko MURAKAMI, Hiroaki IMAGAWA, Norihito SUMIYOSHI, Shoji TAGASHIRA and Yoshiaki \\ SASAKI \\ Department of Chemistry and Earth Sciences, Faculty of Science, Yamaguchi University, 1677-1 Yoshida, \\ Yamaguchi, Yamaguchi 753-8512, Japan
}

(Manuscript submitted February 14, 2003; accepted March 24, 2003)

\begin{abstract}
A layered perovskite type oxide, $\mathrm{HCa}_{2} \mathrm{Nb}_{3} \mathrm{O}_{10}$, can incorporate mono- and divalent metal ions from aqueous solution. $n$-Pentylamine intercalates into the interlayer of $\mathrm{HCa}_{2} \mathrm{Nb}_{3} \mathrm{O}_{10}$ and the resulting oxide had an excellent reactivity for metal ions such as $\mathrm{Cs}^{+}, \mathrm{Ca}^{2+}$ or $\mathrm{Sr}^{2+}$. The mechanism of the intercalation of the metal ions into the hydrophobic interlayer in aqueous medium was studied.
\end{abstract}

\section{Introduction}

$\mathrm{KCa}_{2} \mathrm{Nb}_{3} \mathrm{O}_{10}$ has a structure comprised of perovskite-like layers of $\mathrm{NbO}_{6}$ octahedra with $\mathrm{Ca}^{2+}$ occupying twelve coordinate sites and $\mathrm{K}^{+}$in the interlayer.[1-2] The area of unit layer charge is $0.147 \mathrm{~nm}^{2}$, which is narrower than those of clays such as the smectites, therefore, this compound has the potential to become a high capacity ion-exchanger. The ion-exchange reaction of $\mathrm{KCa}_{2} \mathrm{Nb}_{3} \mathrm{O}_{10}$ with alkali metal ions in the molten state of alkali metal chlorides or nitrates[1], and that of $\mathrm{HCa}_{2} \mathrm{Nb}_{3} \mathrm{O}_{10}$, in which potassium ion was substituted by proton, with alkali metal ions in aqueous medium[3] were performed. In the aqueous medium, the ion-exchange reaction of the interlayer cation incompletely proceeded, in $30-70 \%$, because of the difficulty for hydrated ions to enter or move into the interlayer. Ion-exchange reactions will be promoted by delamination of the layered $\mathrm{HCa}_{2} \mathrm{Nb}_{3} \mathrm{O}_{10}$. Delamination of $\mathrm{HCa}_{2} \mathrm{Nb}_{3} \mathrm{O}_{10}$ is more difficult[4] than that of $\left[\mathrm{Zr}\left(\mathrm{PO}_{4}\right)_{2}\right] \mathrm{H}_{2} \cdot \mathrm{H}_{2} \mathrm{O}[5]$ and $\mathrm{HTiNbO}_{5}[6]$ because of its higher charge, and it is necessary to investigate another approach to promote the ion exchange.

In the present study, we investigated the ion-exchange reactions of $\mathrm{HCa}_{2} \mathrm{Nb}_{3} \mathrm{O}_{10}$ and an amine-intercalate of this oxide with alkali and alkaline earth metal ions in aqueous solutions. Our purpose is to develop these layer compounds into ion exchangers, which can incorporate metal ions from aqueous solutions under mild conditions. The role of amines in the acceleration of the ion-exchange reactions is discussed.

\section{Experimental}

\subsection{Materials}

A mixture of $\mathrm{CaCO}_{3}, \mathrm{~K}_{2} \mathrm{CO}_{3}$, and $\mathrm{Nb}_{2} \mathrm{O}_{5}$ in stoichiometric amounts was ground and fired at $1023 \mathrm{~K}$ for $12 \mathrm{~h}$. After the addition of more $\mathrm{K}_{2} \mathrm{CO}_{3}$ in $20 \%$, the mixture was ground and fired again at $1473 \mathrm{~K}$ for $24 \mathrm{~h}$ to obtain $\mathrm{KCa}_{2} \mathrm{Nb}_{3} \mathrm{O}_{10}$. $\mathrm{HCa}_{2} \mathrm{Nb}_{3} \mathrm{O}_{10}$ was obtained by the treatment of $\mathrm{KCa}_{2} \mathrm{Nb}_{3} \mathrm{O}_{10}$ with $6 \mathrm{~mol} \mathrm{dm}^{-3} \mathrm{HCl}$ at $333 \mathrm{~K}$ for $24 \mathrm{~h}$, filtered off, and dried at $383 \mathrm{~K}$ for $24 \mathrm{~h}$. Alkali and alkaline earth metal solutions were prepared by dissolving the 
metal chlorides in double deionized water except for cesium sulfate. All reagents used were commercially available.

\subsection{Apparatus}

Powder X-ray diffraction patterns were measured with a Rigaku RINT 2000V diffractometer using CuK $\alpha$ radiation. Determination of the metal concentration was carried out with a Shimadzu AA-625 atomic absorption spectrophotometer or Varian Liberty Series II ICP-AES. The amounts of water and organic amine in the solids were analyzed with a Mac Science TG-DTA 2010T-R by heating in air to $1073 \mathrm{~K}$ at $10 \mathrm{~K} \mathrm{~min}^{-1}$.

\subsection{Ion exchange of $\mathrm{HCa}_{2} \mathrm{Nb}_{3} \mathrm{O}_{10}$ with the metal ions}

A $0.1 \mathrm{~g}$ sample of $\mathrm{HCa}_{2} \mathrm{Nb}_{3} \mathrm{O}_{10}$ was equilibrated in a plastic bottle with $20 \mathrm{~cm}^{3}$ of metal solution at $333 \mathrm{~K}$ for $24 \mathrm{~h}$. After centrifugation at $14500 \mathrm{rpm}$ for $10 \mathrm{~min}$, the solid was washed with water and followed by the treatment with $20 \mathrm{~cm}^{3}$ of $6 \mathrm{~mol} \mathrm{dm}^{-3} \mathrm{HCl}$ at $333 \mathrm{~K}$ for $24 \mathrm{~h}$. The metal concentration in the supernatant after each centrifugation was measured.

\subsection{Ion exchange of the amine-intercalated $\mathrm{HCa}_{2} \mathrm{Nb}_{3} \mathrm{O}_{10}$ with the metal ions}

In order to avoid the precipitation of carbonate salts, a series of experiments for the alkaline earth metal ions were carried out under an $\mathrm{N}_{2}$ atmosphere in a glovebox. A $0.1 \mathrm{~g}$ sample of $\mathrm{HCa}_{2} \mathrm{Nb}_{3} \mathrm{O}_{10}$ and appropriate amounts of an amine were added to a plastic bottle. After sealing, the mixture was allowed to stand at room temperature for $2 \mathrm{~h}$. A $20 \mathrm{~cm}^{3}$ of $5 \mathrm{mmol} \mathrm{dm}^{-3}$ of the metal solution was then added and left for $24 \mathrm{~h}$ at $333 \mathrm{~K}$ with occasional shaking. In a similar manner as described above, preparation of the solutions for measurement was performed.

\section{Results and Discussion}

The XRD patterns of $\mathrm{KCa}_{2} \mathrm{Nb}_{3} \mathrm{O}_{10}$ and $\mathrm{HCa}_{2} \mathrm{Nb}_{3} \mathrm{O}_{10}$ dried at $383 \mathrm{~K}$ were in good agreement with those reported in the literature [1-3]. Although the wet $\mathrm{HCa}_{2} \mathrm{Nb}_{3} \mathrm{O}_{10}$ contained 1.5 molecules of $\mathrm{H}_{2} \mathrm{O}$, conversion to the anhydrate at $363 \mathrm{~K}$ was confirmed by the TG-DTA measurements.

\subsection{Ion-exchange of $\mathrm{HCa}_{2} \mathrm{Nb}_{3} \mathrm{O}_{10}$ by the metal ions}

The ion-exchange reaction is expressed as follows.

$\mathrm{P}-\left(\mathrm{H}^{+}\right)_{\mathrm{n}}+\mathrm{M}^{\mathrm{n}} \rightleftharpoons \mathrm{P}-\mathrm{M}^{\mathrm{n}+}+\mathrm{nH}^{+}$

The percentages of ion-exchange, $E$, by $\mathrm{Li}^{+}, \mathrm{Na}^{+}$and $\mathrm{K}^{+}$ were ca. $50 \%$ as shown in Fig. 1, but that by $\mathrm{Cs}^{+}$was $30 \%$. E for $\mathrm{Ba}^{2+}$ attained ca. $100 \%$, and the equilibrium concentrations of the ions remaining in solution were less than sub- $\mu \mathrm{mol} \mathrm{dm}{ }^{-3}$.

In general, the order of the ion-exchange affinity of the

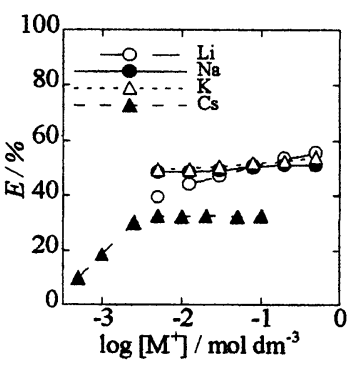

Fig.1 Ion-exchange of $\mathrm{HCa}_{2} \mathrm{Nb}_{3} \mathrm{O}_{10}$ by the alkali and alkaline earth metal ions.

alkali metal ions is $\mathrm{Cs}>\mathrm{K}>\mathrm{Na}>\mathrm{Li}$. This means that a significant hydration of the metal ion reduces their reactivity. But our experiment showed the order of $\mathrm{Na}=\mathrm{K}>\mathrm{Li}>\mathrm{Cs}$, and the affinity with $\mathrm{Cs}^{+}$was the lowest. Any of alkali metal ions could not be substituted for protons completely. The use of alkali hydroxide solutions also did not enhance $E$. The incomplete ion-exchange of $\mathrm{K}^{+}, \mathrm{Rb}^{+}$and $\mathrm{Cs}^{+}$and a low reactivity of $\mathrm{Cs}^{+}$were also pointed out by Jacobson et al.[3] As the high charge density of $\mathrm{HCa}_{2} \mathrm{Nb}_{3} \mathrm{O}_{10}$ did not permit the delamination of the sheet, the metal ions would have difficulty in entering or diffusing in the rigid interlayer of $\mathrm{HCa}_{2} \mathrm{Nb}_{3} \mathrm{O}_{10}$, particularly for $\mathrm{Cs}^{+}$having the largest crystal ionic radius.

\subsection{Intercalation of various amines into $\mathrm{HCa}_{2} \mathrm{Nb}_{3} \mathrm{O}_{10}$}


n-Propyl-, n-butyl-, n-pentyl-, n-hexyl-, n-octyl-, and n-decylamine intercalated into $\mathrm{HCa}_{2} \mathrm{Nb}_{3} \mathrm{O}_{10}$ with basal spacings increasing in this order. The basal spacing $(h / \mathrm{nm})$ of the amine-intercalated $\mathrm{HCa}_{2} \mathrm{Nb}_{3} \mathrm{O}_{10}$ was related to the carbon number of the amine $(n)$ in a linear fashion, i.e., $h=0.243 n+1.45$. The coefficient 0.243 is greater than the $\mathrm{C}-\mathrm{C}$ bond length $(0.154 \mathrm{~nm})$, but smaller than twice the bond length. If the amines are oriented at an angle to the layer, being parallel to each other, and form a bilayer in the interlayer, then the tilting angle can calculate as $53^{\circ}$.

With increasing mole ratio of the n-pentylamine to $\mathrm{HCa}_{2} \mathrm{Nb}_{3} \mathrm{O}_{10}$, the basal spacing had a constant value of $2.69 \mathrm{~nm}$ at mole ratios above 1.0 (Fig.2). From the TG-DTA measurement of the sample obtained at a mole ratio of 2 , it was found that $\mathrm{HCa}_{2} \mathrm{Nb}_{3} \mathrm{O}_{10}$ incorporated 0.7 molecule of n-pentylamine after volatilization of the excess amine at room temperature.

The interlayer amine is fixed by the layer proton. The cross section of the amine $\left(0.20 \mathrm{~nm}^{2}\right)$ is greater than the area of unit layer charge, and amines are likely to form a bilayer in the interlayer at the stoichiometric ratio. If the amines are oriented perpendicular to the sheet, there would be many vacancies in the interlayer. However, it is too narrow to accommodate another amine molecules. Therefore, excess amine did not intercalate and the interlayer amines were oriented at an angle to the sheet to form the bilayer.

The bilayer structure of the amine in the interlayer was confirmed by the XRD patterns of $\mathrm{HCa}_{2} \mathrm{Nb}_{3} \mathrm{O}_{10}$, which was pre-intercalated with 3-fold n-pentylamine and treated with $20 \mathrm{~cm}^{3}$ aqueous solutions of $\mathrm{pH} 3.4-11.3$ for

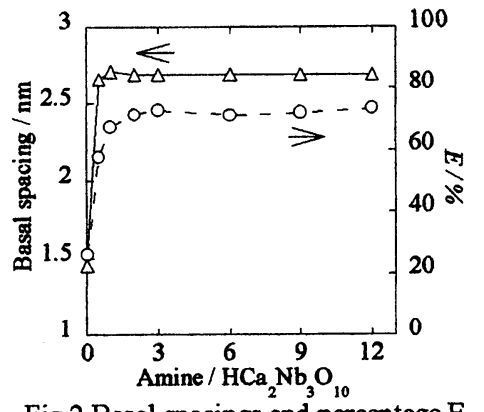

Fig.2 Basal spacings and percentage $E$ of $\mathrm{Sr}^{2+}$ against the amine/ $\mathrm{HCa} \mathrm{Nb}_{3} \mathrm{O}_{10}$ mole rataio.

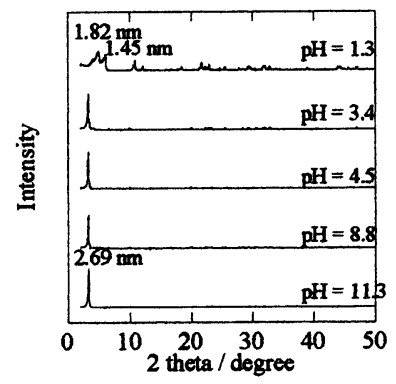

Fig. 3 XRD patterns of the pentylamineintercalated $\mathrm{HCa}_{2} \mathrm{Nb}_{3} \mathrm{O}_{10}$ after reaction with the solutions of various $\mathrm{pH}$.

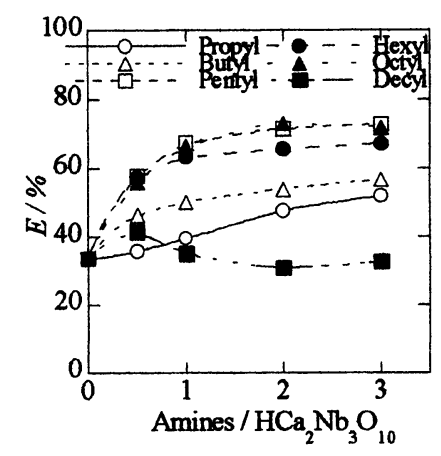

Fig.4 Effect of the molar ratio of n-alkylamines to $\mathrm{HCa}_{2} \mathrm{Nb}_{3} \mathrm{O}_{10}$ on $E$ $24 \mathrm{~h}$ at $333 \mathrm{~K}$.(Fig. 3)

\subsection{Ion exchange of the amine-intercalated $\mathrm{HCa}_{2} \mathrm{Nb}_{3} \mathrm{O}_{10}$ with $\mathrm{Sr}^{2+}$}

We consider the ion-exchange reaction as follows.

$$
\mathrm{P}-\left(\mathrm{H}^{+}-\mathrm{NH}_{2}-\mathrm{R}\right)_{\mathrm{n}}+\mathrm{M}^{\mathrm{n}+}=\mathrm{P}-\mathrm{M}^{\mathrm{n}+}+\mathrm{n}{ }^{+} \mathrm{NH}_{3} \mathrm{R}
$$

Fig. 4 shows the effect of the $n$-alkylamine to $\mathrm{HCa}_{2} \mathrm{Nb}_{3} \mathrm{O}_{10}$ mole ratio on the

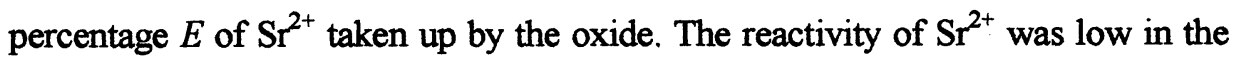
case of the n-propylamine-intercalated $\mathrm{HCa}_{2} \mathrm{Nb}_{3} \mathrm{O}_{10}$, particularly at low amine ratios. The $E$ values of n-pentyl-, n-hexyl-, and n-octylamine became constant at ratio above 2. On the other hand, the $E$ value of n-decylamine showed the lowest value equal to that achieved with $\mathrm{HCa}_{2} \mathrm{Nb}_{3} \mathrm{O}_{10}$. A complete ion exchange of $\mathrm{HCa}_{2} \mathrm{Nb}_{3} \mathrm{O}_{10}$ with $\mathrm{Sr}^{2+}$ was not achieved using any n-alkylamines. Jacobson et al. also tried the exchange of the n-butylamine-intercalated $\mathrm{HCa}_{2} \mathrm{Nb}_{3} \mathrm{O}_{10}$ by $\mathrm{K}^{+}$, but the result was an incomplete exchange.[3]

$\mathrm{n}$-Alkylamines are more or less soluble in aqueous solution. n-Propylamine having a hydrophilic property can easily dissolve, as given by eq. 3 ,

$$
\mathrm{P}-\mathrm{H}^{+}-\mathrm{NH}_{2}-\mathrm{C}_{3} \mathrm{H}_{7}=\mathrm{P}-\mathrm{H}^{+}+\mathrm{NH}_{2} \mathrm{C}_{3} \mathrm{H}_{7}
$$

Therefore most part of $\mathrm{Sr}^{2+}$ reacted with not the amine-intercalated $\mathrm{HCa}_{2} \mathrm{Nb}_{3} \mathrm{O}_{10}$ but $\mathrm{HCa}_{2} \mathrm{Nb}_{3} \mathrm{O}_{10}$. Because the amount of $n$-propylamine that remained in the interlayer increased with the increasing amount of amine added in the solution, then, the percent $\mathrm{E}$ increased. 
The $n$-decylammonium ion in the interlayer was not exchanged with $\mathrm{Sr}^{2+}$ because the $\mathrm{n}$-decylamine is highly stable. The release of $n$-decylamine from the interlayer into the solution was inhibited by the addition of excess amine to the solution.

The ion-exchange reaction in Eq. 2 progressed in the case of the n-pentyl-, n-hexyl-, and n-octylamines. In spite of the low solubility of these amines, they were exchanged with $\mathrm{Sr}^{2+}$. The close stacking of the layers, namely a reduced interlayer distance, causes the layered compounds to become more stable. For hydrophobic amines, their transfer into the interlayer decreases their chemical potentials, but it causes an increase in the chemical potential of the interlayer due to an increased interlayer distance. An ion-exchange reaction will occur when the total chemical potential difference is negative. The total chemical potential difference is given by the changes in the chemical states of the reaction components: for the amines, solution species as monomers and aggregates or interlayer species as bilayer associates; for the interlayer, small or large interlayer distances, and for the metal ions, hydrated or dehydrated states.

\subsection{Ion exchange of the n-pentylamine-intercalated $\mathrm{HCa}_{2} \mathrm{Nb}_{3} \mathrm{O}_{10}$ with $\mathrm{Sr}^{2+}$}

Fig. 2 shows that the increase in the n-pentylamine above 3 lead to a constant $E$ higher than $70 \%$. As the intercalation of more than 1 molecule of amine did not occur, more than 2-fold n-pentylamine in aqueous solution needs to attain a higher $E$ for the exchange of $\mathrm{Sr}^{2+}$. The reaction of the $\mathrm{n}$-pentylamine-intercalated $\mathrm{HCa}_{2} \mathrm{Nb}_{3} \mathrm{O}_{10}$ was faster than that of $\mathrm{HCa}_{2} \mathrm{Nb}_{3} \mathrm{O}_{10}$ at $333 \mathrm{~K}$ (Fig. 5). The peak at 1.62 $\mathrm{nm}$ in the XRD pattern, which corresponds to $\mathrm{Sr}_{1 / 2} \mathrm{Ca}_{2} \mathrm{Nb}_{3} \mathrm{O}_{10}$, appeared within $1 \mathrm{~h}$ for the pre-intercalated $\mathrm{HCa}_{2} \mathrm{Nb}_{3} \mathrm{O}_{10}$, and became higher with time and was accompanied by the decrease in the peak height at $2.69 \mathrm{~nm}$. Moreover, the peak at

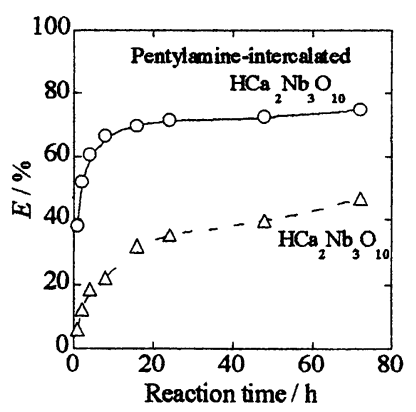

Fig. 5 Effect of the reaction time on $E$. $2.69 \mathrm{~nm}$ remained at least for $72 \mathrm{~h}$.

\subsection{Ion exchange of the n-pentylamine-intercalated} $\mathrm{HCa}_{2} \mathrm{Nb}_{3} \mathrm{O}_{10}$ with metal ions

Fig. 6 shows the reactivity of the n-pentylamine-intercalated $\mathrm{HCa}_{2} \mathrm{Nb}_{3} \mathrm{O}_{10}$ with alkali and alkaline earth metal ions. The intercalation of $n$-pentylamine produced an increase in $E$ for $\mathrm{Cs}^{+}$to the level of the other alkali metal ions. Moreover, $\mathrm{Ca}^{2+}$ could exchange on $\mathrm{HCa}_{2} \mathrm{Nb}_{3} \mathrm{O}_{10}$. More precise experiments for the bivalent metal cation with small ionic radius are now in progress.
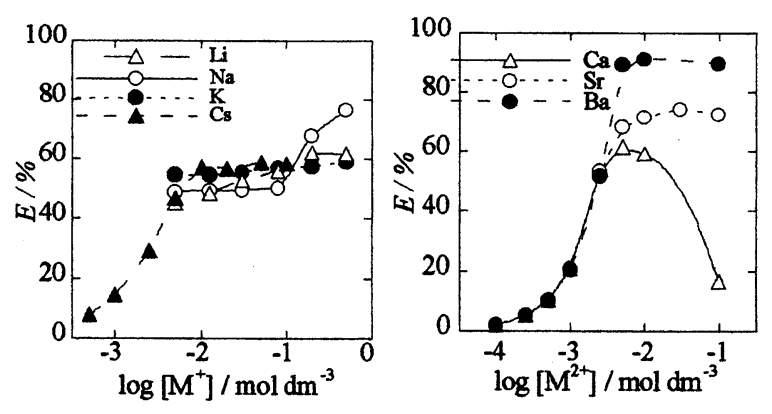

Fig.6 Ion-exchange of the n-pentylamine-intercalated $\mathrm{HCa}_{2} \mathrm{Nb}_{3} \mathrm{O}_{10}$ by the alkali and alkaline earth metal ions.

\section{References}

1) M. Dion, M. Ganne and M. Tournoux, Mat. Res. Bull., 16,1429-1435 (1981).

2) A. J. Jacobson, J. W. Johnson and J. T. Lewandowski, Inorg. Chem., 24, 3727-3729 (1985).

3) A. J. Jacobson, J. T. Lewandowski and J. W. Johnson, Mat. Res. Bull., 25, 679-686 (1990).

4) M. M. H. Treacy, S. B. Rice, A. J. Jacobson and J. T. Lewandowski, Chem. Mater., 2, 279-286 (1990).G.

5) Alberti, M. Casciola and U. Constantino, J. Colloid Interfacial. Sci., 107, 236-263 (1985).

6) H. Rebbah, M. M. Borel and B. Raveau, Mat. Res. Bull., 15, 317-321 (1980).

7) L. Kullberg and A. Clearfield, J. Phys. Chem., 85,1578-1584 (1981). 